\title{
Epidemiology, diagnosis, and management of polycystic ovary syndrome
}

This article was published in the following Dove Press journal:

Clinical Epidemiology

18 December 2013

Number of times this article has been viewed

\author{
Susan M Sirmans \\ Kristen A Pate \\ Department of Clinical and \\ Administrative Sciences, College \\ of Pharmacy, University of Louisiana \\ at Monroe, Monroe, LA, USA
}

\begin{abstract}
Polycystic ovary syndrome (PCOS) is a common heterogeneous endocrine disorder characterized by irregular menses, hyperandrogenism, and polycystic ovaries. The prevalence of PCOS varies depending on which criteria are used to make the diagnosis, but is as high as $15 \%-20 \%$ when the European Society for Human Reproduction and Embryology/American Society for Reproductive Medicine criteria are used. Clinical manifestations include oligomenorrhea or amenorrhea, hirsutism, and frequently infertility. Risk factors for PCOS in adults includes type 1 diabetes, type 2 diabetes, and gestational diabetes. Insulin resistance affects $50 \%-70 \%$ of women with PCOS leading to a number of comorbidities including metabolic syndrome, hypertension, dyslipidemia, glucose intolerance, and diabetes. Studies show that women with PCOS are more likely to have increased coronary artery calcium scores and increased carotid intima-media thickness. Mental health disorders including depression, anxiety, bipolar disorder and binge eating disorder also occur more frequently in women with PCOS. Weight loss improves menstrual irregularities, symptoms of androgen excess, and infertility. Management of clinical manifestations of PCOS includes oral contraceptives for menstrual irregularities and hirsutism. Spironolactone and finasteride are used to treat symptoms of androgen excess. Treatment options for infertility include clomiphene, laparoscopic ovarian drilling, gonadotropins, and assisted reproductive technology. Recent data suggest that letrozole and metformin may play an important role in ovulation induction. Proper diagnosis and management of PCOS is essential to address patient concerns but also to prevent future metabolic, endocrine, psychiatric, and cardiovascular complications.
\end{abstract}

Keywords: polycystic ovary syndrome, diagnosis, comorbidities, epidemiology, management, comorbidities, women's health, hyperandrogenism

\section{Introduction}

Polycystic ovary syndrome (PCOS) was first reported in modern medical literature by Stein and Leventhal who, in 1935, described seven women suffering from amenorrhea, hirsutism, and enlarged ovaries with multiple cysts. ${ }^{1}$ It is now recognized as a common, heterogeneous, heritable disorder affecting women throughout their lifetime. PCOS is characterized by hyperandrogenism, ovulatory dysfunction, and polycystic ovaries. However, there is considerable interindividual variation in presentation. Although not required for diagnosis, the presence of insulin resistance and hyperinsulinemia is common and places those affected at increased risk of diabetes and cardiovascular disease. Thus, PCOS adversely affects endocrine, metabolic, and cardiovascular health.

\section{Clinical features and diagnostic criteria}

The clinical presentation of PCOS varies widely. Women with PCOS often seek care for menstrual disturbances, clinical manifestations of hyperandrogenism, and infertility. 
Menstrual disturbances commonly observed in PCOS include oligomenorrhea, amenorrhea, and prolonged erratic menstrual bleeding. ${ }^{2}$ However, $30 \%$ of women with PCOS will have normal menses. ${ }^{3}$ Approximately $85 \%-90 \%$ of women with oligomenorrhea have PCOS while $30 \%-40 \%$ of women with amenorrhea will have PCOS. ${ }^{4}$

More than $80 \%$ of women presenting with symptoms of androgen excess have PCOS. ${ }^{5}$ Hirsutism is a common clinical presentation of hyperandrogenism occurring in up to $70 \%$ of women with PCOS. ${ }^{6}$ Hirsutism is evaluated using a modified Ferriman-Gallwey scoring system. ${ }^{7}$ This tool is used to evaluate hair growth at seven sites: upper lip, chin/face, chest, back, abdomen, arms, and thighs. A score of 0 is given in the absence of terminal hair growth and a score of 4 is given for extensive growth. A total score of 8 or more is indicative of hirsutism. ${ }^{8}$ Over $90 \%$ of normally menstruating women with hirsutism are identified through ultrasound to have polycystic ovaries. ${ }^{9}$ In addition, PCOS occurs in $50 \%$ of women with less severe distribution of unwanted hair growth. ${ }^{10}$ Acne can also be a marker of hyperandrogenism but is less prevalent in PCOS and less specific than hirsutism. Approximately 15\%-30\% of adult women with PCOS present with acne. ${ }^{5,11}$ The difference in prevalence of hirsutism and acne may be attributed to the difference in expression of $5 \alpha$-reductase in the sebaceous gland and the hair follicle, and resulting higher dihydrotestosterone in the hair follicle. ${ }^{12}$ Of those women presenting with severe acne, over $40 \%$ were diagnosed with PCOS. ${ }^{13}$ Some experts recommend that women presenting with acne be asked about their menstrual history and be evaluated for other signs of hyperandrogenism. ${ }^{12}$

Infertility affects $40 \%$ of women with PCOS. ${ }^{14}$ PCOS is the most common cause of anovulatory infertility. Approximately $90 \%-95 \%$ of anovulatory women presenting to infertility clinics have PCOS. Women with PCOS have a normal number of primordial follicles and primary and secondary follicles are significantly increased. However, due to derangements in factors involved in normal follicular development, follicular growth becomes arrested as follicles reach a diameter of 4-8 $\mathrm{mm}$. Because a dominant follicle does not develop, ovulation does not ensue. ${ }^{14,15}$ In addition, spontaneous abortion occurs more frequently in PCOS with incidences ranging from $42 \%-73 \%{ }^{16,17}$

Diagnostic criteria for PCOS have been offered by three groups: the National Institutes of Health/National Institute of Child Health and Human Disease (NIH/NICHD); ${ }^{18}$ the European Society for Human Reproduction and Embryology/American Society for Reproductive Medicine
(ESHRE/ASRM); ${ }^{19}$ and the Androgen Excess and PCOS Society. ${ }^{20}$ These criteria are summarized in Table 1.

While there are certain consistencies between the criteria offered by the different groups, important differences exist. Each issuing group considers PCOS a diagnosis of exclusion, and other diagnoses, such as congenital adrenal hyperplasia, nonclassic adrenal hyperplasia, Cushing syndrome, androgensecreting tumor, idiopathic hyperandrogenism, idiopathic hirsutism, hyperprolactinemia, and thyroid disorders must be excluded. Because $20 \%-30 \%$ of otherwise normal women have evidence of multiple cysts on their ovaries, ${ }^{20}$ the presence of polycystic ovaries (PCO) alone was not considered sufficient by any group. The NIH/NICHD and the Androgen Excess Society require that patients have signs or symptoms of hyperandrogenism such as hirsutism, or hyperandrogenemia, defined as elevated free testosterone, reduced SHBG (sex hormone-binding globulin), elevated free testosterone index, or elevated dehydroepiandrosterone sulfate. ${ }^{18,20}$ However, ESHRE/ASRM (Rotterdam) criteria allows for the diagnosis of PCOS without the presence of hyperandrogenemia or clinical hyperandrogenism. Women with ovulatory dysfunction and the presence of polycystic ovaries are considered to have PCOS by the Rotterdam criteria. Another key difference between the criteria is how oligomenorrhea or amenorrhea are viewed. The Rotterdam criteria did not require irregular menses or ovulatory dysfunction for diagnosis citing that women with regular menstrual cycles could be considered to have PCOS in the presence of PCO and hyperandrogenemia or hyperandrogenism. ${ }^{19}$ Subclinical ovulatory dysfunction can occur in women with regular menstrual bleeding. ${ }^{20}$ However, $\mathrm{NIH} / \mathrm{NICHD}$ excludes the diagnosis of PCOS in women with regular menses and subclinical ovulatory dysfunction.

Table I Criteria for the diagnosis of polycystic ovary syndrome

\begin{tabular}{|c|c|c|}
\hline $\mathbf{I H}$ & $\begin{array}{l}\text { ESHRE/ASRM } \\
\text { (Rotterdam } \\
\text { criteria) 2004 } \\
\end{array}$ & $\begin{array}{l}\text { Androgen Excess } \\
\text { Society } 2006^{20}\end{array}$ \\
\hline $\begin{array}{l}\text { Exclusion of other } \\
\text { androgen excess or } \\
\text { related disorders }\end{array}$ & $\begin{array}{l}\text { Exclusion of other } \\
\text { androgen excess or } \\
\text { related disorders }\end{array}$ & $\begin{array}{l}\text { Exclusion of other } \\
\text { androgen excess or } \\
\text { related disorders }\end{array}$ \\
\hline Includes all of the & two of the & ll of the \\
\hline $\begin{array}{l}\text { - Clinical and/or } \\
\text { biochemical } \\
\text { hyperandrogenism }\end{array}$ & $\begin{array}{l}\text { - Clinical and/or } \\
\text { biochemical } \\
\text { hyperandrogenism }\end{array}$ & $\begin{array}{l}\text { - Clinical and/or } \\
\text { biochemical } \\
\text { hyperandrogenism }\end{array}$ \\
\hline $\begin{array}{l}\text { - Menstrual } \\
\text { dysfunction }\end{array}$ & $\begin{array}{l}\text { - Oligo-ovulation or } \\
\text { anovulation } \\
\text { - Polycystic ovaries }\end{array}$ & $\begin{array}{l}\text { - Ovarian dysfunction } \\
\text { and/or polycystic } \\
\text { ovaries }\end{array}$ \\
\hline
\end{tabular}

Abbreviations: ESHRE/ASRM, European Society for Human Reproduction and Embryology/American Society for Reproductive Medicine; NIH/NICH, National Institutes of Health/National Institute of Child Health and Human Disease. 
The diagnosis of PCOS using the Rotterdam and AES criteria depends on the use of a reliable method to describe polycystic ovarian morphology. The criteria for polycystic ovarian morphology proposed by the Rotterdam consensus group includes the presence of 12 or more follicles measuring between 2 and $9 \mathrm{~mm}$ in diameter and/or an increased ovarian volume of greater than $10 \mathrm{~cm}^{3}$. This presentation in one ovary sufficiently defines the polycystic ovary. ${ }^{19}$ However, since that time, significant advancements in ultrasound image technology have been made, improving resolution and allowing for the detection of smaller follicles. ${ }^{21}$ This has prompted calls for revisiting the criteria used to define polycystic ovarian morphology. ${ }^{21-23}$ Allemand et al used three-dimensional transvaginal ultrasound to measure the mean follicle number per ovary (FNPO) and the maximum number of follicles in a single sonographic plane in ten patients with diagnosed PCOS and 29 normoandrogenic ovulatory controls. ${ }^{23} \mathrm{~A}$ mean FNPO of $\geq 20.1$ identified PCO with $100 \%$ specificity and $70 \%$ sensitivity. A maximum number of follicles in a single sonographic plane of ten identified PCO with $100 \%$ specificity and $90 \%$ sensitivity. Ovarian volume, measured by two-dimensional transvaginal ultrasound, of $\geq 13.0 \mathrm{~cm}^{3}$ predicted PCO with a specificity of $100 \%$ and a sensitivity of $50 \%$. Using two-dimensional transvaginal ultrasound, Dewailly et al measured the total number of all follicles that were less than $10 \mathrm{~mm}$ in diameter throughout the ovary and also measured the ovarian volume. ${ }^{22} \mathrm{~A}$ threshold follicle number of 19 had a sensitivity for predicting PCO of $81 \%$ and a specificity of $92 \%$. Ovarian volume of $7 \mathrm{~cm}^{3}$ predicted PCO with a sensitivity of $87 \%$ and a specificity of $89 \%$. Lujan et al measured FNPO, follicle counts in a single cross section, and ovarian volume in images that were digitally archived for offline analysis. ${ }^{21}$ In their analysis, a FNPO threshold of 26 follicles had a sensitivity of $85 \%$ and specificity of $94 \%$ in discriminating between subjects with PCOS and controls. A threshold of nine follicles for follicle counts in a single cross section had a sensitivity of $69 \%$ and specificity of $90 \%$. The threshold for ovarian volume of $10 \mathrm{~cm}^{3}$ yielded a sensitivity of $81 \%$ and a specificity of $84 \%$.

\section{Epidemiology and risk factors}

Prevalence estimates for PCOS, as defined by the NIH/NICHD criteria, indicate that PCOS is a common endocrinopathy affecting 4\%-8\% of women of reproductive age. ${ }^{24-28}$ Recently, several groups have demonstrated that the prevalence of PCOS varies depending on the diagnostic criteria used (see Table 2). ${ }^{29-32}$ These studies consistently report that the prevalence estimates using the Rotterdam criteria are two to three times greater than those obtained using the NIH/NICHD criteria.

Family history of PCOS is a risk factor for PCOS. Based on the clustering of cases in families, PCOS is considered to be a heritable disorder. ${ }^{33,34} \mathrm{~A}$ high prevalence of PCOS or its features among first-degree relatives is suggestive of genetic influences. ${ }^{35,36} \mathrm{In}$ addition, greater concordance has been reported in monozygotic twins versus dizygotic twins. ${ }^{37}$ However, the mode of inheritance remains elusive. Issues that hamper progress in this area include the heterogeneity of PCOS phenotypes, difficulty in assigning a phenotype to men, postmenopausal women, and prepubertal girls, and difficulties in obtaining large enough sample sizes to allow for adequate statistical power. ${ }^{38} \mathrm{~A}$ genome wide association study conducted amongst Han Chinese has identified loci on chromosomes $2 \mathrm{p} 16.3,2 \mathrm{p} 21$, and $9 \mathrm{q} 33.3 .{ }^{39}$ Some of these results were replicated in European cohorts, namely the chromosome 2p21 THADA and chromosome 9p33.3 DENND1A susceptibility loci. The sharing of the same susceptibility genes suggests that PCOS is an ancient disorder originating before humans migrated out of Africa. ${ }^{40}$

An increased prevalence of PCOS is associated with a number of conditions. A history of weight gain often precedes the development of the clinical features of PCOS, ${ }^{41}$ and following a healthy lifestyle has been shown to reduce body weight, abdominal fat, reduce testosterone, improve insulin resistance, and decrease hirsutism in women with PCOS..$^{42}$ Obese women referred for assistance with weight loss had a prevalence of PCOS of $28.3 \%{ }^{43}$ However, in an unselected population, prevalence of PCOS did not vary significantly based on obesity class. ${ }^{44} \mathrm{PCOS}$ prevalence rates for underweight, normal-weight, overweight, mildly obese, moderately obese, and severely obese

Table 2 Prevalence of polycystic ovary syndrome (PCOS) using different diagnostic criteria

\begin{tabular}{|c|c|c|c|c|}
\hline Source & Population & NIH/NICHD criteria & $\begin{array}{l}\text { ESHRE/ASRM } \\
\text { (Rotterdam) criteria }\end{array}$ & $\begin{array}{l}\text { Androgen excess and } \\
\text { PCOS society criteria }\end{array}$ \\
\hline March et $\mathrm{al}^{29}$ & 728 Australian women & $8.7 \%$ & $17.8 \%$ & $12.0 \%$ \\
\hline Mehrabian et $\mathrm{a}^{30}$ & 820 Iranian women & $7 \%$ & $15.2 \%$ & $7.92 \%$ \\
\hline Tehrani et $\mathrm{al}^{31}$ & 929 Iranian women & $7.1 \%$ & $14.6 \%$ & $11.7 \%$ \\
\hline Yildiz et a $\left.\right|^{32}$ & 392 Turkish women & $6.1 \%$ & $19.9 \%$ & $15.3 \%$ \\
\hline
\end{tabular}

Abbreviations: ESHRE/ASRM, European Society for Human Reproduction and Embryology/American Society for Reproductive Medicine; NIH/NICHD, National Institutes of Health/National Institute of Child Health and Human Disease. 
women were $8.2 \%, 9.8 \%, 9.9 \%, 5.2 \%, 12.4 \%$, and $11.5 \%$, respectively. The authors concluded that obesity may increase the risk of PCOS but that the effect was modest.

An increased frequency of reproductive disorders, including PCOS, has been reported in women with epilepsy. ${ }^{45}$ Using NIH criteria for diagnosis, Bilo et $\mathrm{al}^{46}$ identified PCOS in 13 of 50 women $(26 \%)$ with epilepsy. Among the 16 patients who were not treated for epilepsy at presentation, five (31\%) were diagnosed with PCOS, supporting the contention that epilepsy, independent of antiepileptic drugs, increases the risk of PCOS. Valproic acid, an antiepileptic drug widely used to treat epilepsy, bipolar disorder, and migraine, is associated with features of polycystic ovary syndrome when used to treat women with epilepsy. These features include menstrual disturbances, polycystic ovarian morphology, and elevated serum testosterone. ${ }^{47,48}$ Substitution of lamotrigine for valproic acid in women with epilepsy resulted in reductions in body mass index, fasting serum insulin, and testosterone concentrations. ${ }^{49}$ Thus, the confounding effects of medication must be considered when evaluating the literature that probes the relationship between epilepsy, bipolar disorder, and PCOS.

Type 1, Type 2, and gestational diabetes have been associated with an increased prevalence of PCOS. Escobar-Morreale et al screened 85 Caucasian women with type 1 diabetes mellitus for PCOS using the NIH/NICHD criteria. ${ }^{50}$ PCOS was diagnosed in 16 of these women (18.8\%). Subsequently, Codner et al screened 42 women with type 1 diabetes mellitus and 38 age and body mass index (BMI) matched controls for PCOS using the ESHRE/ASRM criteria. ${ }^{51}$ The prevalence of PCOS was $40.5 \%$ in the type 1 diabetes group and $2.6 \%$ in the control group, yielding a relative risk of PCOS of 15.4 (95\% confidence interval $[\mathrm{CI}] 2.2-110.2 ; P<0.0001$ ) in the type 1 diabetes group. In type 2 diabetes, $\mathrm{PCO}$ are extremely common, occurring in $82 \%$ of women. ${ }^{52}$ The prevalence of PCOS in type 2 diabetes using the NIH/NICHD criteria has been estimated to be $26.7 \% .^{53} \mathrm{~A}$ diagnosis of PCOS was verified in 15 of 94 women (16\%) with gestational diabetes and in six of $94(6.4 \%)$ of those without gestational diabetes $(P=0.03) .{ }^{54}$

A number of factors that are associated with an increased risk of PCOS have been identified in children. ${ }^{55}$ Prenatal factors include high birth weight in girls born to overweight mothers, congenital virilization, and low birth weight. Risk factors apparent later in childhood include premature pubarche, atypical central precocious puberty, obesity syndromes, acanthosis nigricans, and metabolic syndrome. A high index of suspicion for the diagnosis of
PCOS is warranted in adolescents with persistently irregular menses and these risk factors. ${ }^{56}$

\section{Association of PCOS with other comorbidities}

Although the demonstration of insulin resistance is not required to make the diagnosis of PCOS, it is clear that hyperinsulinemic insulin resistance plays a prominent role in PCOS. The prevalence of insulin resistance in PCOS ranges from 50\%-70\% $\%^{57-60}$ and occurs independently of obesity. ${ }^{61}$ The effect of obesity on insulin resistance is additive to that of PCOS. ${ }^{61}$ Consistent with the increased prevalence of insulin resistance, metabolic syndrome is also more common in women with PCOS. A meta-analysis performed for studies with BMI-matched controls showed that PCOS is associated with a higher prevalence of metabolic syndrome compared to women without PCOS (odds ratio [OR] 2.20, 95\% CI 1.36-3.56). Lean women with PCOS were also more likely to have metabolic syndrome than lean women without PCOS (OR 3.00, 95\% CI 1.24-6.78). ${ }^{62}$ The components of metabolic syndrome are associated with insulin resistance and are summarized in Table $3 .^{63}$

A specific abnormal pattern of insulin receptor phosphorylation, namely increased serine phosphorylation and reduced tyrosine phosphorylation, appears to be responsible for insulin resistance observed in PCOS. ${ }^{64}$ However, insulin's effect on steroidogenesis in the ovarian theca cells is not adversely affected. Hyperinsulinemia produces a hyperandrogenic state by acting as a cogonadotropin with luteinizing hormone (LH), increasing androgen production by theca cells and by reducing

Table 3 Clinical identification of the metabolic syndrome

\begin{tabular}{ll}
\hline Abdominal obesity* (waist circumference)** & \\
Men & $>102 \mathrm{~cm}(>40 \mathrm{in})$ \\
Women & $>88 \mathrm{~cm}(>35 \mathrm{in})$ \\
Triglycerides & $\geq 150 \mathrm{mg} / \mathrm{dL}$ \\
High-density lipoprotein cholesterol & $<40 \mathrm{mg} / \mathrm{dL}$ \\
Men & $<50 \mathrm{mg} / \mathrm{dL}$ \\
Women & $\geq 130 / \geq 85 \mathrm{mmHg}$ \\
Blood pressure & $\geq 110 \mathrm{mg} / \mathrm{dL}$ \\
\hline Fasting glucose
\end{tabular}

Notes: *Overweight and obesity are associated with insulin resistance and the metabolic syndrome. However, the presence of abdominal obesity is more highly correlated with the metabolic risk factors than is an elevated body mass index (BMI). Therefore, the simple measure of waist circumference is recommended to identify the body weight component of the metabolic syndrome. **Some male patients can develop multiple metabolic risk factors when the waist circumference is only marginally increased, eg, 94-102 cm (37-40 in). Such patients may have strong genetic contribution to insulin resistance and they should benefit from changes in life habits, similarly to men with categorical increases in waist circumference. Reproduced from NCEP Expert Panel on Detection, Evaluation, and Treatment of High Blood Cholesterol in Adults. Executive Summary of The Third Report of The National Cholesterol Education Program (NCEP) Expert Panel on Detection, Evaluation, And Treatment of High Blood Cholesterol In Adults (Adult Treatment Panel III). JAMA. 200 ; 285: 2486-2497. ${ }^{3}$ Copyright (C) (200I) American Medical Association. All rights reserved. 
hepatic production of sex hormone binding globulin, resulting in higher concentrations of free androgens. ${ }^{65}$

Independent of obesity, PCOS is associated with a higher prevalence of impaired glucose tolerance and type 2 diabetes. Although most women with PCOS maintain sufficient betacell function to prevent deterioration in glucose tolerance, a significant proportion, especially those with first degree relatives with type 2 diabetes, demonstrate abnormal beta-cell response in response to glucose challenge or meals. ${ }^{66-70}$ In women with PCOS and normal glucose tolerance at baseline, $16 \%$ converted to impaired glucose tolerance per year; women with impaired glucose converted to type 2 diabetes at a rate of $2 \%$ per year. $^{71}$ Approximately $30 \%-40 \%$ of women with PCOS have impaired glucose tolerance and $7.5 \%-10 \%$ have type 2 diabetes. ${ }^{72,73}$ These rates are substantially higher than the $7.8 \%$ rate of impaired glucose tolerance and $2.5 \%$ rate of diabetes observed in women of similar age in the Second National Health and Nutrition Survey. ${ }^{74}$ In a recent meta-analysis, a subgroup analysis of BMI-matched studies reported the OR for impaired glucose tolerance was 2.54 (95\% CI 1.54-4.47) for women with PCOS.${ }^{62}$ When evaluating only lean subjects, the OR for impaired glucose tolerance was 3.22 (95\% CI 1.26-8.24). The same meta-analysis evaluated the prevalence of type 2 diabetes in BMI-matched studies and reported a higher prevalence of type 2 diabetes in PCOS (OR 4.0, 95\% CI 1.97-8.1).

An increased risk of dyslipidemia has been demonstrated in PCOS. Lipid abnormalities include reduced high density lipoprotein-cholesterol (HDL-C), increased triglycerides, and increased low density lipoprotein-cholesterol (LDL-C). A recent meta-analysis by Wild et al evaluated the difference in lipoproteins from women age 18-45 years with PCOS compared to controls from the same catchment area. ${ }^{75}$ Triglycerides were $26.39 \mathrm{mg} / \mathrm{dL}$ (95\% CI 17.24-35.54) higher and HDL-C was $6.41 \mathrm{mg} / \mathrm{dL}$ (95\% CI 3.68-9.14) lower in PCOS. LDL-C was $12.60 \mathrm{mg} / \mathrm{dL}$ (95\% CI 9.51-15.69) higher in PCOS. The difference in LDL-C was greater when the NIH/NICHD criteria were used to identify PCOS (14.95 mg/dL [95\% CI 13.08-16.82]) than when the ESHRE/ASRM criteria were used $(8.35 \mathrm{mg} / \mathrm{dL}$ [95\% CI 5.16-11.54]). In addition, studies have revealed the presence of highly atherogenic small dense low density lipoprotein (LDL) in women with PCOS. ${ }^{76-78}$ Obesity and insulin resistance promote a high hepatic triglyceride content, which, in turn, leads to increased hepatic secretion of very low density lipoprotein (VLDL) particles. Insulin resistance is also associated with reduced clearance of VLDL particles and chylomicrons by reducing the activity of lipoprotein lipase, increasing levels of apolipoprotein C-III, and impairing apolipoprotein E-mediated clearance of triglyceride rich lipoproteins. In addition, hepatic triglyceride content determines the size of the VLDL particles produced by the liver. When the hepatic content of triglycerides is high, larger VLDL particles are produced. Metabolism of these large particles results in the formation of small, dense LDL particles that are poorly cleared and more atherogenic. ${ }^{79}$

Several studies conclude that women with PCOS have an increased prevalence of hypertension. Potential mechanisms of hypertension in PCOS include endothelial dysfunction, as evidenced by increased endothelin- 1 levels ${ }^{80}$ and increased aldosterone concentrations related to insulin resistance. ${ }^{81}$ However, many of these studies did not control for obesity; a common comorbidity in PCOS and a well-known risk factor for hypertension. ${ }^{82}$ Lo et al reported that women with PCOS were more likely to have hypertension or elevated blood pressure than controls after adjusting for BMI category, age, diabetes, and dyslipidemia (adjusted OR 1.53, 95\% CI 1.31-1.51). ${ }^{83}$ Czech women with PCOS were also more likely to have hypertension compared to controls. ${ }^{84}$ Hypertension was present in $22 \%$ of the women with PCOS compared to $2.1 \%$ of controls. Mean systolic and mean diastolic blood pressures remained significantly higher in the PCOS group after adjusting for BMI. In a study of Dutch women aged 45-54 years, the prevalence of hypertension was $28.1 \%$ in the PCOS group and $11.1 \%$ in the control group. ${ }^{85}$ In this age group, the proportion of obese PCOS women did not differ from the control group.

Despite the apparent clustering of cardiovascular risk factors in PCOS, evidence that PCOS is associated with increased cardiovascular events is scarce. A retrospective cohort study by Wild et al was unable to demonstrate a significant increase in coronary heart disease morbidity and mortality in women with PCOS. ${ }^{86}$ However, cerebrovascular disease was more prevalent in women with PCOS after adjustment for BMI (OR 3.4, 95\% CI 1.2-9.6). Results from a prospective 21-year follow-up study of 35 women with PCOS who had undergone ovarian wedge resection up to 31 years previously did not demonstrate an increase in cardiovascular events compared to 120 age-matched controls. ${ }^{87}$ In contrast, Shaw et al reported a 3.3-fold greater risk for cardiovascular death or myocardial infarction in 104 postmenopausal women with a history of irregular menses and hyperandrogenemia ${ }^{88}$ Event free survival was significantly reduced after adjusting for age, obesity, diabetes and angiographically-demonstrated cardiovascular disease. This is consistent with a study that evaluated the relationship between menstrual cycle irregularity and risk for cardiovascular disease ${ }^{89}$ Participants included 82,439 women enrolled in the Nurses' Health Study ${ }^{90}$ who responded to a question regarding menstrual cycle regularity at ages 20-35 years. Women responding that their menstrual 
cycles were usually irregular comprised $10.9 \%$ of the participants while $4.3 \%$ of the participants indicated that their menstrual cycles were very irregular. The age-adjusted relative risk (RR) for total coronary heart disease events was 1.25 (95\% CI 1.07-1.47) for those women reporting usually irregular menstrual cycles and $1.67 \%$ (95\% CI 1.35-2.06) for those with very irregular menstrual cycles. Stroke was not significantly elevated in women with irregular menses.

Noninvasive assessments, including coronary artery calcium (CAC) scores and carotid intima-media thickness (CIMT), have demonstrated a greater prevalence of subclinical atherosclerosis in PCOS. CAC scores are predictive of myocardial infarction and sudden cardiac death. ${ }^{91}$ The increase in CAC scores observed in PCOS is independent of age and BMI. ${ }^{92-95}$ CIMT is positively associated with stroke and myocardial infarction and is a reliable measure of atherosclerosis. ${ }^{96}$ Young women with PCOS have a greater CIMT compared to age- and BMI-matched controls..$^{81,97-100}$ Some experts recommend that CIMT be measured in women with PCOS at age 30 and every $3-5$ years after, and that CAC be measured by computed tomography by age $45 .{ }^{101}$

Women with PCOS are also at increased risk of a number of mental health disorders including depression, bipolar disorder, anxiety, and eating disorders. During systematic screening, Hollinrake et al demonstrated that $35 \%$ of women with PCOS suffered from depression compared to $10.7 \%$ in controls $(P<0.0001){ }^{102}$ After controlling for BMI, family history of depression, and history of infertility, the adjusted OR for overall depressive disorders in women with PCOS was 4.23 (95\% CI $1.49-11.98)$. These results were consistent with those of a recent meta-analysis that reported an OR for abnormal depression scores in women with PCOS of 4.03 (95\% CI 2.96-5.50). ${ }^{103}$ Klipstein and Goldberg screened 78 attendees of the Polycystic Ovarian Syndrome Association regional meetings for bipolar disorders. ${ }^{104}$ Subjects were considered to have bipolar disorder if they had a previous diagnosis by a mental health professional or a positive screen on the Mood Disorders Questionnaire. Approximately $27 \%$ of participants were classified as having bipolar disorder. Use of valproate prior to the diagnosis of PCOS was reported in two of the subjects. Using the Mini International Neuropsychiatric Interview, Rassi et al reported that $11.1 \%$ of women with PCOS receiving care in an outpatient endocrine clinic met the criteria for bipolar disorder types I or II. ${ }^{105}$ Prevalence estimates of bipolar disorder in the general population range from $0.5 \%-2 \% .{ }^{106}$ Results from screenings in women with PCOS for anxiety disorders have also been reported. Prevalence estimates of abnormal anxiety scores in PCOS vary widely and range from $13 \%-63 \% .{ }^{107} \mathrm{~A}$ recent meta-analysis indicated that anxiety is more common in women with PCOS compared to controls (OR 6.88, 95\% CI 2.5-18.94) ${ }^{107}$ Binge eating disorder also appears to be more common in PCOS with $12.6 \%$ of women with PCOS affected compared to $1.9 \%$ of controls. ${ }^{102}$

\section{Outline of management strategies for PCOS}

The choice of treatment for women with PCOS depends on the symptoms with which a patient presents. Symptoms typically fit into three categories: menstruation related disorders; androgen-related symptoms; and infertility. ${ }^{108}$ Management strategies for these characteristic symptoms of PCOS are described below.

\section{Treatment of androgen-related symptoms}

The most common androgen-related symptoms associated with PCOS are acne, hirsutism, and alopecia. The symptoms vary for each patient; some patients present with only one or two symptoms, while a few patients complain of all three. Typically, oral contraceptive pills (OCPs) are first-line for pharmacologic management of hirsutism in premenopausal women. ${ }^{108}$ Women often use laser hair removal and other mechanical hair removal options because pharmacologic treatments do not produce the results they desire. ${ }^{109}$ It generally takes at least 6 months of treatment to see a response due to the growth cycle of hair. ${ }^{6}$ Antiandrogens can be added if there has been no improvement after 6 months of treatment. OCPs and antiandrogens have both been effective in the treatment of acne. ${ }^{108}$ In severe acne, isotretinoin may offer benefits for some patients. ${ }^{6}$ There is limited data for treatment of alopecia, but OCPs and androgen blockers are used. ${ }^{108}$

Combined hormonal contraceptive (CHC) OCPs are a good treatment option for those patients that do not wish to become pregnant, and they are often considered first line for the treatment of PCOS-related hirsutism and acne. CHCs promote negative feedback on the production of $\mathrm{LH}$, causing a decreased synthesis of androgens by the ovaries. Other mechanisms by which $\mathrm{CHCs}$ reduce androgens include: 1) decreasing circulating levels of free androgen by increasing the production of sex hormone-binding globulin in the liver; 2) decreasing adrenal androgen secretion; and 3) inhibiting peripheral conversion of testosterone to dihydrotestosterone and binding of dihydrotestosterone to androgen receptors. Progestins have varying degrees of androgenic effects. Newer OCPs typically contain less androgenic progestins such as norethindrone, desogestrel, and norgestimate. ${ }^{108}$ Drospirenone is a newer progestin that functions as an androgen receptor antagonist, and it is a spironolactone 
analog with antimineralocorticoid activity. Caution should be used in patients at an increased risk of hyperkalemia, and potassium should be monitored in patients also taking spironolactone. ${ }^{108,109}$ Dienogest is another newer progestin that has antiandrogenic properties. ${ }^{108}$ There is no definitive evidence that there are differences in efficacy among low dose CHCs. Although there are risks associated with $\mathrm{CHCs}$, the benefits seem to outweigh the risks in the majority of patients with PCOS. ${ }^{6}$

Spironolactone, an aldosterone antagonist, is an antiandrogen that primarily acts by binding to the androgen receptor as an antagonist. It also inhibits ovarian and adrenal steroidogenesis, directly inhibits 5 - $\alpha$-reductase activity, and competes for androgen receptors in hair follicles. ${ }^{108,109}$ Doses of 25-200 mg per day in one to two divided doses are used. ${ }^{110}$ Due to the fact that, when used alone, it can cause menstrual irregularity and has the risk of feminizing a male fetus if the patient becomes pregnant, spironolactone is commonly used in combination with OCPs for treatment of PCOS related symptoms. ${ }^{108,109}$ Spironolactone can cause hyperkalemia, and, thus, should be used with caution in patients with renal impairment. ${ }^{109}$ Finasteride is an antiandrogen that competitively inhibits tissue and hepatic 5 - $\alpha$-reductase resulting in inhibition of the conversion of testosterone to dihydrotestosterone and suppression of serum dihydrotestosterone levels. ${ }^{109,110}$ Finasteride is pregnancy category $\mathrm{X}$ due to the risk of feminizing a male fetus if pregnancy occurs. Patients on finasteride should use adequate contraception, with OCPs as an option that could potentially offer synergistic effects. ${ }^{108,109}$

Metformin and thiazolidinediones have insulin-lowering effects by improving insulin sensitivity, and in turn can decrease circulating androgen levels. ${ }^{108}$ Additionally, these agents have a role in the treatment of PCOS due to the fact that women with PCOS are at an increased risk of insulin resistance, and in turn the development of metabolic disorders and cardiovascular disease. ${ }^{109}$ Although no antidiabetic agents have US Food and Drug Administration approval for the treatment of PCOS, metformin is preferred at this time due to the fact that it appears to have the safest risk-benefit ratio, and it can cause weight loss, while thiazolidinediones can increase weight as a result of fluid retention. ${ }^{109}$

Eflornithine is a topical cream that has been approved by the US Food and Drug Administration for removal of unwanted facial hair in females. ${ }^{108,109}$ Eflornithine inhibits the enzyme ornithine decarboxylase in the skin, which inhibits cell division and synthetic functions, thus reducing the rate of hair growth. It should be used twice daily, at least 8 hours apart, on the affected areas of the face and chin. ${ }^{108,110}$

\section{Treatment of menstruation- related disorders}

Along with patient complaints of menstrual irregularity, the often chronic anovulation that is associated with PCOS can increase a patient's risk of endometrial hyperplasia and carcinoma. Using either cyclic progestin or a low dose $\mathrm{CHC}$ containing estrogen and progestin can help inhibit endometrial proliferation. ${ }^{108}$ Low dose $\mathrm{CHCs}$ are the primary recommended treatment option for PCOS-related menstrual disorders and improved menstrual regularity. ${ }^{109}$

Weight loss can improve circulating androgen levels, along with providing numerous other metabolic benefits for patients with PCOS. ${ }^{108}$ The benefits of weight loss can be evident with a loss of 5\% of initial body weight. ${ }^{109}$ An additional treatment that is gaining popularity is acupuncture. The primary benefits that have been suggested with acupuncture are reduced hyperandrogenism and improved menstrual regularity. ${ }^{108,111}$

\section{Treatment of infertility}

Weight loss is recommended as first-line therapy for the management of infertility in overweight and obese women with PCOS. Anovulation ${ }^{112}$ and pregnancy loss ${ }^{113}$ are linked with obesity. In addition, obesity is associated with a reduced response to fertility treatments including clomiphene citrate, ${ }^{114,115}$ gonadotropins, ${ }^{116,117}$ and laparoscopic ovarian diathermy. ${ }^{118}$ Observational studies indicate that weight loss of $5 \%-10 \%$ can increase ovulation and pregnancies. ${ }^{119}$ Bariatric surgery has been shown to improve cycle regularity, increase ovulation, and increase spontaneous conception. ${ }^{120-122}$

Clomiphene citrate is the drug of first choice for ovulation induction in women with PCOS. ${ }^{123}$ Clomiphene citrate is a partially selective estrogen receptor modulator. Its antiestrogenic activity at the hypothalamus induces a change in gonadotropin releasing hormone $(\mathrm{GnRH})$ pulse frequency leading to increased release of follicle stimulating hormone (FSH) from the pituitary gland. The ovulation rate with clomiphene ranges from $70 \%-85 \%$ per cycle, while the cumulative live birth rate ranges from $50 \%-60 \%$ for treatment up to six cycles. ${ }^{124}$ The starting dose of clomiphene citrate is $50 \mathrm{mg}$ per day for 5 days starting on days 2-5 following a spontaneous or progestin-induced withdrawal bleeding. If ovulation does not ensue, the dose is increased by $50 \mathrm{mg}$ per cycle to a maximum dose of $150 \mathrm{mg}$ /day. The maximum number of cycles is generally limited to six ovulatory cycles. ${ }^{123}$ If 
ovulation cannot be induced at doses of $150 \mathrm{mg} / \mathrm{day}$, the patient is considered to be clomiphene resistant. Failure to achieve pregnancy after six ovulatory cycles is classified as a clomiphene failure. ${ }^{125}$

Metformin is a biguanide commonly used as an antihyperglycemic agent. It has been extensively evaluated in PCOS associated infertility. In its 2008 consensus statement, the ESHRE/ASRM concluded that metformin is less effective than clomiphene in inducing ovulation and that there was no advantage to adding metformin to clomiphene. ${ }^{123}$ In a meta-analysis of randomized controlled trials, metformin improved ovulation rate and clinical pregnancy rate but not live birth rate when compared to placebo or no treatment. ${ }^{126}$ However, in a recent multicenter, randomized, double-blind, placebo-controlled study, metformin increased live-birth rates compared to placebo $(41.9 \%$ versus $28.8 \%, P=0.014)$ with the most beneficial effect seen in obese women. ${ }^{127}$ These results are consistent with another study that evaluated pretreatment with metformin for 3 months before in vitro fertilization/intracytoplasmic sperm injection (IVF/ICSI). ${ }^{128}$ Although the role of metformin for ovulation induction in PCOS has been limited, these results suggest that metformin may play an important role in improving live birth rates when administered 3 months prior to and concurrent with standard infertility treatments.

Aromatase inhibitors block the conversion testosterone and androstenedione to estradiol and estrone, respectively. This decrease in estrogenic activity releases the hypothalamus from negative feedback, allowing for an increase in the release of FSH. ${ }^{129}$ Letrozole, the most commonly used aromatase inhibitor for ovulation induction, is administered in doses between $2.5-7.5 \mathrm{mg}$ per day for 5 days starting on day 3 of the menstrual cycle. ${ }^{130}$ Putative advantages of letrozole include its lack of antiestrogenic effects on the endometrium, ${ }^{131}$ shorter half-life when compared to clomiphene and a higher rate of monofollicular ovulation. ${ }^{129} \mathrm{~A}$ recent systematic review and meta-analysis of randomized controlled trials that compared letrozole with clomiphene indicated that letrozole administration was associated with a higher ovulation rate per person. However, letrozole did not increase ovulation per cycle, pregnancy, or live birth rate per person. ${ }^{132}$ Since that review, a study comparing clomiphene citrate with letrozole in 103 treatment-naïve infertile women with PCOS demonstrated that letrozole use was associated with a similar ovulation rate $(73.08 \%$ in the letrozole group versus $60.78 \%$ in the clomiphene group, $P=0.39)$ but significantly higher pregnancy rate $(21.56 \%$ in the letrozole group versus $7.84 \%$ in the clomiphene group,
$P=0.015) .{ }^{133}$ The Pregnancy in Polycystic Ovary Syndrome II study targeted 750 infertile women with PCOS to compare the rate of live birth for clomiphene versus letrozole. ${ }^{134}$ The results of this trial will clarify the role of letrozole for ovulation induction in women with PCOS.

Ovulation induction with gonadotropins and laparoscopic ovarian drilling (LOD) are considered to be second line therapies for ovulation induction by the ESHRE/ ASRM. ${ }^{123}$ The gonadotropin approach is less invasive and is the preferred treatment in women who do not desire surgery. LOD is preferred when the patient has other indications for surgery or when the patient is not able to comply with the frequent follow-up visits required with gonadotropin therapy. ${ }^{135}$

The goal of FSH administration for ovulation induction is the development of a single follicle resulting in a singleton live birth. Risks associated with ovulation induction include ovarian hyperstimulation syndrome (OHSS) and pregnancy with multiples. Because women with PCOS are very sensitive to the effects of FSH, a low-dose step-up protocol is recommended. ${ }^{123,136}$ The starting dose of FSH of 37.5-50 IU daily is increased in increments of 25-37.5 IU at 7-14 day intervals until follicular development is observed. Serial ultrasound and serum estradiol concentrations are used to guide FSH dose titration and to determine when human chorionic gonadotropin should be administered to trigger ovulation. ${ }^{137}$ Cycle cancellation is advised if more than two follicles are greater than $16 \mathrm{~mm}$ or one follicle is greater than $16 \mathrm{~mm}$ and two other follicles are greater than $14 \mathrm{~mm} .{ }^{123}$ A recent study compared the efficacy of clomiphene versus low-dose step-up FSH protocol for up to three cycles as first line therapy for the treatment of infertility in anovulatory women with PCOS. Per protocol analysis indicated that the low-dose step-up FSH protocol produced a higher pregnancy rate in the first cycle ( $30 \%$ versus $14.6 \%, P=0.003$ ), a higher cumulative pregnancy rate $(52.1 \%$ versus $41.2 \%, P=0.021)$, and a higher cumulative live birth rate $(47.4 \%$ versus $36.9 \%$, $P=0.031) .{ }^{138}$ However, clomiphene treatment is more convenient and less costly than gonadotropin therapy.

LOD involves the use of laser or electrocautery to drill four to ten holes in the surface and the stroma of the ovary. It is indicated for the treatment of infertility in clomipheneresistant PCOS. ${ }^{123}$ A single treatment results in the establishment of ovulatory menstrual cycles in $92 \%$ of women, and pregnancy in $58 \% .{ }^{139}$ Predictors of a poor response to LOD include a body mass index of $\geq 35 \mathrm{~kg} / \mathrm{m}^{2}$, serum testosterone concentrations of $\geq 4.5 \mathrm{nmol} / \mathrm{L}$, free androgen index $\geq 15$, and a duration of infertility of $>3$ years. Serum LH 
concentrations $\geq 10 \mathrm{IU} / \mathrm{L}$ at baseline are associated with a significantly greater likelihood of pregnancy. ${ }^{140}$ When LOD was compared to clomiphene as first line therapy, no difference was observed in ovulation or pregnancy between the two treatments. ${ }^{141}$ A Cochrane review indicated that LOD rivals the pregnancy rate and live birth rate of three to six cycles of gonadotropins without putting the patient at risk for OHSS or multiple births. ${ }^{142} \mathrm{~A}$ recent systematic review and meta-analysis compared LOD with or without medical ovulation induction therapy to pharmacologic ovulation induction in clomiphene resistant PCOS and found no difference in ovulation rate or live birth rate between the groups. However, no cases of OHSS were observed in the LOD group and multiple pregnancy occurred less frequently with LOD (OR 0.21, 95\% CI 0.08-0.58, P=0.002). ${ }^{143}$

In-vitro fertilization (IVF) is recommended as thirdline therapy for the management of infertility by the 2008 Thessaloniki ESHRE/ASRM-Sponsored PCOS Consensus Workshop Group. ${ }^{123}$ Women with PCOS have similar pregnancy, miscarriage, and live-birth rates with conventional IVF compared to non-PCOS patients. ${ }^{144}$ Women with PCOS experienced more cycle cancellations. In addition more oocytes were retrieved per cycle with a lower fertilization rate in women with PCOS. In a recent Cochrane review comparing the GnRH antagonist protocol with the long GnRH agonist protocol in women with PCOS undergoing IVF/ICSI treatment, no significant difference was found in ongoing pregnancy rate or clinical pregnancy rate. However, the rate of OHSS was $10 \%$ lower with the antagonist protocol. ${ }^{145}$ In a randomized, double-blind, placebo-controlled trial, metformin $500 \mathrm{mg}$ three times per day significantly reduced the risk of OHSS (RR 0.28, 95\% CI 0.11-0.67) in women with PCOS undergoing IVF/ICSI who were at high risk for OHSS. ${ }^{146}$

\section{Conclusion}

Proper diagnosis and management of PCOS is essential as PCOS has many potential metabolic and cardiovascular risks if not managed appropriately. ${ }^{109}$ It is clear that the underlying pathophysiology of PCOS is not fully understood. ${ }^{108}$ As a result, treatment is often focused on individual symptoms, not the syndrome itself. However, as the understanding of the pathophysiology of PCOS improves, so does the treatment. Although treatment should be individualized, it should also focus on all metabolic consequences and decreasing future complications. ${ }^{147}$ More extensive research and understanding of the pathophysiology of PCOS will improve treatment success and overall management of patients. ${ }^{108}$

\section{Disclosure}

The authors report no conflicts of interest in this work.

\section{References}

1. Stein IF, Leventhal ML. Amenorrhea associated with bilateral polycystic ovaries. Am J Obstet Gynecol. 1935;29:181-191.

2. Farquhar C. Introduction and history of polycystic ovary syndrome. In: Kovacs G, Norman R, editors. Polycystic Ovary Syndrome. 2nd ed. Cambridge, UK: Cambridge University Press; 2007:4-24.

3. Balen A, Conway G, Kaltsas G. Polycystic ovary syndrome: the spectrum of the disorder in 1741 patients. Hum Reprod. 1995;10:2107-2111.

4. Hart R. Definitions, prevalence and symptoms of polycystic ovaries and the polycystic ovary syndrome. In: Allahbadia GN, Agrawal R, editors. Polycystic Ovary Syndrome. Kent, UK: Anshan, Ltd; 2007:15-26.

5. Azziz R, Sanchez L, Knochenhauer ES, et al. Androgen excess in women: experience with over 1000 consecutive patients. $J$ Clin Endocrinol Metab. 2004;89(2):453-462.

6. Fauser B, Tarlatzis B, Rebar R, et al. Consensus on women's health aspects of polycystic ovary syndrome (PCOS): the Amsterdam ESHRE/ ASRM-Sponsored 3rd PCOS Consensus Workshop Group. Fertil Steril. 2012;97(1):28-38. e25.

7. Ferriman D, Gallwey J. Clinical assessment of body hair growth in women. J Clin Endocrinol Metab. 1961;21:1440-1447.

8. Unluhizarci K, Kaltsas G, Kelestimur F. Non polycystic ovary syndrome-related endocrine disorders associated with hirsutism. Eur J Clin Invest. 2012;42(1):86-94.

9. Adams J, Polson D, Franks S. Prevalence of polycystic ovaries in women with anovulation and idiopathic hirsutism. Br Med J (Clin Res Ed). 1986;293(6543):355-359.

10. Souter I, Sanchez L, Perez M, Bartolucci A, Azziz R. The prevalence of androgen excess among patients with minimal unwanted hair growth. Am J Obstet Gynecol. 2004;191:1914-1920.

11. Wijeyaratne CN, Balen AH, Barth JH, Belchetz PE. Clinical manifestations and insulin resistance (IR) in polycystic ovary syndrome (PCOS) among south Asians and Caucasians: is there a difference? Clin Endocrinol (Oxf). 2002;57:343-350.

12. Lowenstein E. Diagnosis and management of the dermatologic manifestations of the polycystic ovary syndrome. Dermatol Ther. 2006;19(4):210-223.

13. Eden J. The polycystic ovary syndrome presenting as resistant acne successfully treated with cyproterone acetate. Med J Aust. 1991;155(10):677-680.

14. Teede H, Deeks A, Moran L. Polycystic ovary syndrome: a complex condition with psychological, reproductive and metabolic manifestations that impacts on health across the lifespan. BMC Med. 2010;8:41.

15. Brassard M, AinMelk Y, Baillargeon JP. Basic infertility including polycystic ovary syndrome. Med Clin North Am. 2008;92: 1163-1192.

16. Glueck C, Phillips H, Cameron D, Sieve-Smith L, Wang P. Continuing metformin throughout pregnancy in women with polycystic ovary syndrome appears to safely reduce first-trimester spontaneous abortion: a pilot study. Fertil Steril. 2001;75(1):46-52.

17. Jakubowicz DJ, Iuorno MJ, Jakubowicz S, Roberts K, Nestler JE. Effects of metformin on early pregnancy loss in the polycystic ovary syndrome. J Clin Endocrinol Metab. 2002;87(2):524-529.

18. Zawadski JK, Dunaif A. Diagnostic criteria for polycystic ovary syndrome. In: Givens JHF, Merriman G, editors. The Polycystic Ovary Syndrome. Cambridge, MA: Blackwell Scientific; 1992:377-384.

19. Rotterdam ESHRE/ASRM-Sponsored PCOS Consensus Workshop Group. Revised 2003 consensus on diagnostic criteria and longterm health risks related to polycystic ovary syndrome. Fertil Steril. 2004;81:19-25.

20. Azziz R, Carmina E, DeWailly D, et al. Position statement: criteria for defining polycystic ovary syndrome as a predominantly hyperandrogenic syndrome: an Androgen Excess Society guideline. J Clin Endocrinol Metab. 2006;91:4237-4245. 
21. Lujan ME, Jarrett BY, Brooks ED, et al. Updated ultrasound criteria for polycystic ovary syndrome: reliable thresholds for elevated follicle population and ovarian volume. Hum Reprod. 2013;28(5):1361-1368.

22. Dewailly D, Gronier H, Poncelet E, et al. Diagnosis of polycystic ovary syndrome (PCOS): revisiting the threshold values of follicle count on ultrasound and of the serum AMH level for the definition of polycystic ovaries. Hum Reprod. 2011;26(11):3123-3129.

23. Allemand MC, Tummon IS, Phy JL, Foong SC, Dumesic DA, Session DR. Diagnosis of polycystic ovaries by three-dimensional transvaginal ultrasound. Fertil Steril. 2006;85(1):214-219.

24. Azziz R, Woods KS, Reyna R, Key TJ, Knochenhauer ES, Yildiz BO. The prevalence and features of the polycystic ovary syndrome in an unselected population. J Clin Endocrinol Metab. 2004;89:2745-2749.

25. Diamanti-Kandarakis E, Kouli CR, Bergiele AT, et al. A survey of the polycystic ovary syndrome in the Greek island of Lesbos: hormonal and metabolic profile. J Clin Endocrinol Metab. 1999;84: 4006-4011.

26. Knochenhauer ES, Key TJ, Kahsar-Miller M, Waggoner W, Boots LR, Azziz R. Prevalence of the polycystic ovary syndrome in unselected black and white women of the southeastern United States: a prospective study. J Clin Endocrinol Metab. 1998;83:3078-3082.

27. Michelmore KF, Balen AH, Dunger DB, Vessey MP. Polycystic ovaries and associated clinical and biochemical features in young women. Clin Endocrinol (Oxf). 1999;51:779-786.

28. Asuncion M, Calvo RM, San Millan JL, Sancho J, Avila S, EscobarMorreale HF. A prospective study of the prevalence of the polycystic ovary syndrome in unselected Caucasian women from Spain. J Clin Endocrinol Metab. 2000;85:2434-2438.

29. March WA, Moore VM, Willson KJ, Phillips DI, Norman RJ, Davies MJ. The prevalence of polycystic ovary syndrome in a community sample assessed under contrasting diagnostic criteria. Hum Reprod. 2010;25(2): 544-551.

30. Mehrabian F, Khani B, Kelishadi R, Ghanbari E. The prevalence of polycystic ovary syndrome in Iranian women based on different diagnostic criteria. Endokrynol Pol. 2011;62(3):238-242.

31. Tehrani FR, Simbar M, Tohidi M, Hoseinpanah F, Azizi F. The prevalence of polycystic ovary syndrome in a community sample of Iranian population: Iranian PCOS prevalence study. Reprod Biol Endocrinol. 2011;9:39.

32. Yildiz BO, Bozdag G, Yapici Z, Esinler I, Yarali H. Prevalence, phenotype and cardiometabolic risk of polycystic ovary syndrome under different diagnostic criteria. Hum Reprod. 2012;27(10):3067-3073.

33. Franks S, Gharani N, Waterworth D, et al. The genetic basis of polycystic ovary syndrome. Hum Reprod. 1997;12:2641-2648.

34. Legro RS, Driscoll D, Straus III JF, Fox J, Dunaif A. Evidence for a genetic basis for hyperandrogenemia in polycystic ovary syndrome. Proc Natl Acad Sci U S A. 1998;95:14956-14960.

35. Amato P, Simpson JL. The genetics of polycystic ovary syndrome. Best Pract Res Clin Obstet Gynaecol. 2004;18(5):707-718.

36. Crosignani PG, Nicolosi AE. Polycystic ovarian disease: heritability and heterogeneity. Hum Reprod Update. 2001;7(1):3-7.

37. Vink JM, Sadrzadeh S, Lambalk CB, Boomsma DI. Heritability of polycystic ovary syndrome in a Dutch twin-family study. $J$ Clin Endocrinol Metab. 2006;91(6):2100-2104.

38. Goodarzi MO, Dumesic DA, Chazenbalk G, Azziz R. Polycystic ovary syndrome: etiology, pathogenesis and diagnosis. Nat Rev Endocrinol. 2011;7:219-231.

39. Chen ZJ, Zhao H, He L, et al. Genome-wide association study identifies susceptibility loci for polycystic ovary syndrome on chromosome 2p16.3, 2p21 and 9q33.3. Nat Genet. 2011;43:55-59.

40. Diamanti-Kandarakis E, Dunaif A. Insulin resistance and the polycystic ovary syndrome revisited: An update on mechanism and implication. Endocrine Reviews. 2012;33(6):981-1030.

41. Isikoglu M, Berkkanoglu M, Cemal H, Ozgur K. Polycystic ovary syndrome: What is the role of obesity? In: Allahbadia GN, Agrawal R, editors. Polycystic Ovary Syndrome. Kent, UK: Anshan, Ltd; 2007:157-163.
42. Moran LJ, Hutchison SK, Norman RJ, Teede HJ. Lifestyle changes in women with polycystic ovary syndrome. Cochrane Database Syst Rev. 2011;(7):CD007506.

43. Alvarez-Blasco F, Botella-Carretero JI, San Millan JL, Escobar-Morreale H. Prevalence and characteristics of the polycystic ovary syndrome in overweight and obese women. Arch Intern Med. 2006;166:2081-2086.

44. Yildiz B, Knochenhauer ES, Azziz R. Impact of obesity on the risk for polycystic ovary syndrome. J Clin Endocrinol Metab. 2008;93(1): $162-168$.

45. Herzog AG. Menstrual disorders in women with epilepsy. Neurology. 2006;66(6 Suppl 3):S23-S28.

46. Bilo L, Meo R, Valentino R, Di Carlo C, Striano S, Nappi C. Characterization of reproductive endocrine disorders in women with epilepsy. J Clin Endocrinol Metab. 2001;86:2950-2956.

47. Betts T, Yarrow H, Dutton N, Greenhill L, Rolfe T. A study of anticonvulsant medication on ovarian function in a group of women with epilepsy who have only ever taken one anticonvulsant compared with a group of women without epilepsy. Seizure. 2003;12:323-329.

48. Isojarvi JI, Laatikainen TJ, Pakarinen AJ, Juntenen KT, Myllya VV. Polycystic ovaries and hyperandrogenism in women taking valproate for epilepsy. N Engl J Med. 1993;329:1383-1388.

49. Isojarvi JI, Rattya J, Myllyla W, et al. Valproate, lamotrigine, and insulin-mediated risks in women with epilepsy. Ann Neurol. 1998;43(4): 446-451.

50. Escobar-Morreale HF, Roldan B, Barrio R, et al. High prevalence of the polycystic ovary syndrome and hirsutism in women with type 1 diabetes mellitus. J Clin Endocrinol Metab. 2000;85(11):4182-4187.

51. Codner E, Soto N, Lopez P, et al. Diagnostic criteria for polycystic ovary syndrome and ovarian morphology in women with type 1 diabetes mellitus. J Clin Endocrinol Metab. 2006;91(6):2250-2256.

52. Conn JJ, Jacobs HS, Conway GS. The prevalence of polycystic ovaries in women with type 2 diabetes mellitus. Clin Endocrinol (Oxf). 2000;52(1):81-86.

53. Peppard HR, Marfori J, Iuorno MJ, Nestler JE. Prevalence of polycystic ovary syndrome among premenopausal women with type 2 diabetes. Diabetes Care. 2001;24:1050-1052.

54. Kashanian M, Fazy Z, Pirak A. Evaluation of the relationship between gestational diabetes and a history of polycystic ovarian syndrome. Diabetes Res Clin Pract. 2008;80(2):289-292.

55. Rosenfield RL. Clinical review: identifying children at risk for polycystic ovary syndrome. J Clin Endocrinol Metab. 2007;92(3):787-796.

56. Nicandri KF, Hoeger K. Diagnosis and treatment of polycystic ovarian syndrome in adolescents. Curr Opin Endocrinol Diabetes Obes. 2012;19(6):497-504.

57. DunaifA. Insulin resistance and the polycystic ovary syndrome: mechanism and implications for pathogenesis. Endocrin Rev. 1997;18: 774-800.

58. Carmina E, Lobo R. Use of fasting blood to assess the prevalence of insulin resistance in women with polycystic ovary syndrome. Fertil Steril. 2004;82:661-665.

59. Schachter M, Raziel A, Friedler S, Strassburger D, Bern O, Ron-El R. Insulin resistance in patients with polycystic ovary syndrome is associated with elevated plasma homocysteine. Hum Reprod. 2003;18:721-727.

60. Yildiz BO, Haznedaroglu IC, Kirazli S, Bayraktar M. Global fibrinolytic capacity is decreased in polycystic ovary syndrome, suggesting a prothrombotic state. J Clin Endocrinol Metab. 2002;87:3871-3875.

61. Dunaif A, Sega KR, Futterweit W, Dobrjansky A. Profound peripheral insulin resistance, independent of obesity, in polycystic ovary syndrome. Diabetes. 1989;38:1165-1174.

62. Moran LJ, Misso ML, Wild RA, Norman RJ. Impaired glucose tolerance, type 2 diabetes and metabolic syndrome: a systematic review and metaanalysis. Hum Reprod Update. 2010;16(4):347-363.

63. NCEP Expert Panel on Detection, Evaluation, and Treatment of High Blood Cholesterol in Adults. Executive Summary of The Third Report of The National Cholesterol Education Program (NCEP) Expert Panel on Detection, Evaluation, And Treatment of High Blood Cholesterol In Adults (Adult Treatment Panel III). JAMA. 2001;285:2486-2497. 
64. Dunaif A, Xia J, Book CB, Schenker E, Tang Z. Excessive insulin receptor serine phosphorylation in cultured fibroblasts and in skeletal muscle. A potential mechanism for insulin resistance in the polycystic ovary syndrome. J Clin Invest. 1995;96:801-810.

65. Abdallah MA, Awwad J. The pathophysiology of polycystic ovary syndrome. In: Allahbadia GN, Agrawal R, editors. Polycystic Ovary Syndrome. Kent, UK: Anshan, Ltd; 2007:93-101.

66. Ehrmann D, Sturis J, Byrne M, Karrison T, Rosenfield R, Polonsky K. Insulin secretory defects in polycystic ovary syndrome: relationship to insulin sensitivity and family history of non-insulin dependent diabetes mellitus. J Clin Invest. 1995;96:520-527.

67. O'Meara NM, Blackman JD, Erhman DA. Defects in $\beta$-cell function and insulin action in functional ovarian hyperandrogenism. $J$ Clin Endocrinol Metab. 1993;76:1241-1247.

68. Ehrmann DA, Breda E, Cavaghan MK, et al. Insulin secretory responses to rising and falling glucose concentrations are delayed in subjects with impaired glucose tolerance Diabetologica. 2002;45(4):509-517.

69. Ehrmann DA, Breda E, Corcoran MC, et al. Impaired beta-cell compensation to dexamethasone-induced hyperglycemia in women with polycystic ovary syndrome. Am J Physiol Endocrinol Metab. 2004;287(2):E241-E246.

70. Dunaif A, Finegood DT. $\beta$-cell dysfunction independent of obesity and glucose intolerance in the polycystic ovary syndrome. J Clin Endocrinol Metab. 1996;81:942-947.

71. Legro RS, Gnatuk CL, Kunselman AR, Dunaif A. Changes in glucose tolerance over time in women with polycystic ovary syndrome: a controlled study. J Clin Endocrinol Metab. 2005;90:3236-3242.

72. Ehrmann DA, Barnes RB, Rosenfield RL, Cavaghan MK, Imperial J. Prevalence of impaired glucose tolerance and diabetes in women with polycystic ovary syndrome. Diabetes Care. 1999;22:141-146.

73. Legro RS, Kunselman AR, Dodson WC, Dunaif A. Prevalence and predictors of risk for type 2 diabetes mellitus and impaired glucose tolerance in polycystic ovary syndrome: A prospective, controlled study in 254 affected women. J Clin Endocrinol Metab. 1999;84:165-169.

74. Harris MI, Hadden WC, Knowler WC, Bennett PH. Prevalence of diabetes and impaired glucose tolerance and plasma glucose levels in U.S. population aged 20-74 yr. Diabetes. 1987;36:523-534.

75. Wild RA, Rizzo M, Clifton S, Carmina E. Lipid levels in polycystic ovary syndrome: systematic review and meta-analysis. Fertil Steril. 2011;95(3):1073-1079.

76. Legro RS, Blanche P, Krauss RM, Lobo RA. Alterations in low-density lipoprotein and high-density lipoprotein subclasses among Hispanic women with polycytic ovary syndrome: influence of insulin and genetic factors. Fertil Steril. 1999;72(6):990-995.

77. Dejager S, Pichard C, Giral P, et al. Smaller LDL particle size in women with polycystic ovary syndrome compared to controls. Clin Endocrinol (Oxf). 2001;54(4):455-462.

78. Pirwany IR, Fleming R, Greer IA, Packard CJ, Sattar N. Lipids and lipoprotein subfractions in women with PCOS: relationship to metabolic and endocrine parameters. Clin Endocrinol (Oxf). 2001;54(4):447-453.

79. Krauss RM, Siri PW. Metabolic abnormalities: triglyceride and lowdensity lipoprotein. Endocrinol Metab Clin N Am. 2004;33:405-415.

80. Diamanti-Kandarakis E, Spina G, Kouli C, Migdalism I. Increased endothelin-1 levels in women with polycystic ovary syndrome and the beneficial effect of metformin therapy. J Clin Endocrinol Metab. 2001;86(10):4666-4673.

81. Cascella T, Palomba S, Tauchmanova L, et al. Serum aldosterone concentration and cardiovascular risk in women with polycystic ovarian syndrome. J Clin Endocrinol Metab. 2006;91:4395-4400.

82. Bentley-Lewis R, Seely E, Dunaif A. Ovarian hypertension: polycystic ovary syndrome. Endocrinol Metab Clin North Am. 2011;40: 433-449.

83. Lo JC, Feigenbaum SL, Yand J, Pressman AR, Selby JV, Go AS Epidemiology and adverse cardiovascular risk profile of diagnosed polycystic ovary syndrome. J Clin Endocrinol Metab. 2006;91:1357-1363.

84. Vrbikova J, Cifkova R, Jirkovska A, et al. Cardiovascular risk factors in young Czech females with polycystic ovary syndrome. Hum Reprod. 2003;18(5):980-894.
85. Elting MW, Korsen TJM, Bezemer PD, Schoemaker J. Prevalence of diabetes mellitus, hypertension and cardiac complaints in a follow-up study of Dutch PCOS population. Hum Reprod. 2001;16: 556-560

86. Wild S, Pierpoint T, McKeigue P, Jacobs H. Cardiovascular disease in women with polycystic ovary syndrome at long-term follow-up: a retrospective cohort study. Clin Endocrinol (Oxf). 2000;52: 595-600.

87. Schmidt J, Landin-Wilhelmsen K, Brannstrom M, Dahlgren E. Cardiovascular disease and risk factors in PCOS women of postmenopausal age: a 21-year controlled follow-up study. J Clin Endocrinol Metab. 2011;96(12):3794-3803.

88. Shaw LJ, Bairey Merz CN, Azziz R, et al. Postmenopausal women with a history of irregular menses and elevated androgen measurements at high risk for worsening cardiovascular event-free survival: Results from the National Institutes of Health-National Heart, Lung, and Blood Institute Sponsored Women's Ischemia Syndrome Evaluation. J Clin Endocrinol Metab. 2008;93:1276-1284.

89. Solomon CG, Hu FB, Dunaif A, et al. Menstrual cycle irregularity and risk for future cardiovascular disease. J Clin Endocrinol Metab. 2002;87:2013-2017.

90. Belanger CF, Hennekens CH, Rosner B, Speizer FE. The nurses' health study. Am J Nurs. 1978;78:1039-1040.

91. Arad Y, Spadaro LA, Goodman K, Newstein D, Guerci AD. Prediction of coronary events with electron beam computed tomography. J Am Coll Cardiol. 2000;36:1253-1260.

92. Christian RC, Dumesic DA, Behrenbeck T, Oberg AL, Sheedy PF, Fitzpatrick LA. Prevalence and predictors of coronary artery calcification in women with polycystic ovary syndrome. J Clin Endocrinol Metab. 2003;88:2562-2568.

93. TalbottEO, Zborowski JV, Rager JR, Boudreaux MY, Edmundowicz DA, Guzick DS. Evidence for an association between metabolic cardiovascular syndrome and coronary and aortic calcification among women with polycystic ovary syndrome. J Clin Endocrinol Metab. 2004;89:5454-5461.

94. Shroff R, Kerchner A, Maifeld M, Van Beek E, Jagasia D, Dokras A. Young obese women with polycystic ovary syndrome have evidence of early coronary atherosclerosis. J Clin Endocrinol Metab. 2007;92: 4609-4614.

95. Talbott EO, Zborowski JV, Rager J, Stragand JR. Is there an independent effect of polycystic ovary syndrome (PCOS) and menopause on the prevalence of subclinical atherosclerosis in middle aged women? Vasc Health Risk Manag. 2008;4:453-462.

96. Talbott EO, Guzick DS, Sutton-Tyrrell K, et al. Evidence for association between polycystic ovary syndrome and premature carotid atherosclerosis in middle-aged women. Arteriosler Thromb Vasc Biol. 2000;20: 2414-2421.

97. Guzick DS, Talbot EO, Sutton-Tyrrell K. Carotid atherosclerosis in women with polycystic ovary syndrome: initial results from a casecontrol study. Am J Obstet Gynecol. 1996;174:1224-1232.

98. Carmina E, Orio F, Palomba S, et al. Endothelial dysfunction in PCOS: role of obesity and adipose hormones. Am J Med. 2006;119:356. e351-e356.

99. Vryonidou A, Papatheodorou A, Tavridou A, et al. Association of hyperandrogenemic and metabolic phenotype with carotid intimamedia thickness in young women with polycystic ovary syndrome. $J$ Clin Endocrinol Metab. 2005;2005:2740-2746.

100. Orio F Jr, Palomba S, Cascella T, et al. Early impairment of endothelial structure and function in young normal-weight women with polycystic ovary syndrome. J Clin Endocrinol Metab. 2004;89:4588-4593.

101. Alexander CJ, Tangchitnob EP, Lepor NE. Polycystic ovary syndrome: a major unrecognized cardiovascular risk factor in women. Rev Obstet Gynecol. 2009;2(4):232-239.

102. Hollinrake E, Abreu A, Maifeld M, Van Voorhis BJ, Dokras A. Increased risk of depressive disorders in women with polycystic ovary syndrome. Fertil Steril. 2007;87:1369-1376. 
103. Dokras A, Clifton S, Futterweit W, Wild R. Increased risk for abnormal depression scores in women with polycystic ovary syndrome: a systematic review and meta-analysis. Obstet Gynecol. 2011;117(1): $145-152$.

104. Klipstein KG, Goldberg JF. Screening for bipolar disorder in women with polycystic ovary syndrome: a pilot study. J Affect Disord. 2006;91(2-3):205-209.

105. Rassi A, Veras AB, dos Reis M, et al. Prevalence of psychiatric disorders in patients with polycystic ovary syndrome. Compr Psychiatry. 2010;51:599-602.

106. Merikangas KR, Spence A, Kupfer DJ. Linkage studies of bipolar disorder: methodologic and analytic issues. Arch Gen Psychiatry. 1989;46:1137-1141.

107. Dokras A, Clifton S, Futterweit W, Wild R. Increased prevalence of anxiety symptoms in women with polycystic ovary syndrome: systematic review and meta-analysis. Fertil Steril. 2012;97(1):225-230.

108. Badawy A, Elnashar A. Treatment options for polycystic ovary syndrome. Int J Womens Health. 2011;3:25-35.

109. ACOG Committee on Practice Bulletins - Gynecology. ACOG Practice Bulletin No 108: Polycystic ovary syndrome. Obstet Gynecol. 2009;114(4):936-949.

110. Lexi-Comp Online ${ }^{\mathrm{TM}}$, Lexi-Drugs Online ${ }^{\mathrm{TM}}$. Hudson, Ohio: Lexi-Comp, Inc; August 9, 2013.

111. Bates GW, Propst AM. Polycystic ovarian syndrome management options. Obstet Gynecol Clin North Am. 2012;39(4):495-506.

112. Pasquali R, Pelusi C, Genghini S, Caciari M, Gambineri A. Obesity and reproductive disorders in women. Hum Reprod Update. 2003;9(4): 359-372.

113. Froen JF, Arnestad M, Frey K, Vege A, Saugstad OD, Stray-Pedersen B. Risk factors for sudden intrauterine unexplained death: epidemiologic characteristics of singleton cases in Oslo, Norway,1986-1995. Am J Obstet Gynecol. 2001;184(4):694-702.

114. Imani B, Eijkemans MJ, te Velde ER, Habbema JD, Fauser BC. Predictors of patients remaining anovulatory during clomiphene citrate induction of ovulation in nomogonadotropic oligoamenorrheic infertility. J Clin Endocrinol Metab. 1998;83(7):2361-2365.

115. Imani B, Eijkemans MJ, te Velde ER, Habbema JD, Fauser BC. Predictors of chances to conceive in ovulatory patients during clomiphene citrate induction of ovulation in normogonadotropic oligoamenorheic infertility. J Clin Endocrinol Metab. 1999;84(5):1617-1622.

116. Mulders AG, Laven JS, Eijkemans MJ, Hughes EG, Fauser BC. Patient predictors for outcome of gonadotrophin ovulation induction in women with normogonadotrophic anovulatory infertility: a meta-analysis. Hum Reprod Update. 2003;9(5):429-449.

117. Balen AH, Platteau P, Andersen AN, Devroey P, Sorensen P, Helmgaard L. The influence of body weight on response to ovulation induction with gonadotrophin in 335 women with World Health Organization group II anovulatory infertility. BJOG. 2006;113:1195-1202.

118. Gjonnaess H. Ovarian electrocautery in the treatment of women with polycystic ovary syndrome (PCOS). Factors affecting the results. Acta Obstet Gynecol Scand. 1994;73(5):407-412.

119. Homburg R. The management of infertility associated with polycystic ovary syndrome. Reprod Biol Endocrinol. 2003;1:109.

120. Escobar-Morreale HF, Botella-Carretero JI, Alvarez-Blasco F, Sancho J, San Millan JL. The polycystic ovary syndrome associated with morbid obesity may resolve after weight loss induced by bariatric surgery. J Clin Endocrinol Metab. 2005;90(12):6364-6369.

121. Eid GM, Cottam DR, Velcu LM, et al. Effective treatment of polycystic ovarian syndrome with Roux-en-Y gastric bypass. Surg Obes Relat Dis. 2005;1(2):77-80.

122. Jamal M, Gunay Y, Capper A, Eid A, Heitshusen D, Samuel I. Rouxen-Y gastric bypass ameliorates polycystic ovary syndrome and dramatically improves conception rates: a 9-year analysis. Surg Obes Relat Dis. 2012;8(4):440-444.

123. Thessaloniki ESHRE/ASRM-Sponsored PCOS Consensus Workshop Group. Consensus on infertility treatment related to polycystic ovary syndrome. Fertil Steril. 2008;89(3):505-522.
124. Balen AH. Ovulation induction in the management of anovulatory polycystic ovary syndrome. Mol Cell Endocrinol. 2013;373(1-2):77-82.

125. Costello MF, Misso ML, Wong J, et al. The treatment of infertility in polycystic ovary syndrome: a brief update. Aust NZJObstet Gynaecol. 2012;52:400-403.

126. Tang T, Lord JM, Norman RJ, Yasmin E, Balen AH. Insulin-sensitising drugs (metformin, rosiglitazone, pioglitazone, D-chiroinositol) for women with polycystic ovary syndrome, oligo amenorrhoea and subfertility. Cochrane Database Syst Rev. 2012;5:CD003053.

127. Morin-Papunen L, Rantala AS, Unkila-Kallio L, et al. Metformin improves pregnancy and live-birth rates in women with polycystic ovary syndrome (PCOS): a multicenter, double-blind, placebocontrolled randomized trial. J Clin Endocrinol Metab. 2012;97: 1492-1500.

128. Kjotrod SB, Carlsen SM, Rasmussen PE, et al. Use of metformin before and during assisted reproductive technology in non-obese young infertile women with polycystic ovary syndrome: a prospective, randomized, double-blind, multi-centre study. Hum Reprod. 2011;26(8):2045-2053.

129. Casper RF, Mitwally MF. Use of the aromatase inhibitor letrozole for ovulation induction in women with polycystic ovarian syndrome. Clin Obstet Gynecol. 2011;54(4):685-695.

130. Pritts EA. Letrozole for ovulation induction and controlled ovarian hyperstimulation. Curr Opin Obstet Gynecol. 2010;22(4):289-294.

131. Holzer H, Casper R, Tulandi T. A new era in ovulation induction. Fertil Steril. 2006;85(2):277-284.

132. Misso ML, Wong JL, Teede HJ, et al. Aromatase inhibitors for PCOS: a systematic review and meta-analysis. Hum Reprod Update. 2012;18(3):301-312.

133. Kar S. Clomiphene citrate or letrozole as first-line ovulation induction drug in infertile PCOS women. J Hum Reprod Sci. 2012;5(3): 262-265.

134. Legro RS, Kunselman AR, Brzyski RG, et al. The pregnancy in polycystic ovary syndrome II (PPCOS II) trial: rationale and design of a double-blind randomized trial of clomiphene and letrozole for the treatment of infertility in women with polycystic ovary syndrome. Contemp Clin Trials. 2012;33(3):470-481.

135. Perales-Puchalt A, Legro RS. Ovulation induction in women with polycystic ovary syndrome. Steroids. 2013;78:767-772.

136. Christin-Maitre S, Hugues JN. A comparative randomized multicentric study comparing the step-up versus step-down protocol in polycystic ovary syndrome. Hum Reprod. 2003;18(8):1626-1631.

137. Homburg R. Ovulation induction for women with polycystic ovary syndrome. In: Kovacs G, Norman R, editors. Polycystic Ovary Syndrome. 2nd ed. Cambridge, UK: Cambridge University Press; 2007:140-158.

138. Homburg R, Hendriks ML, Konig TE, et al. Clomifene citrate or low-dose FSH for the first-line treatment of infertile women with anovulation associated with polycystic ovary syndrome: a prospective randomized multinational study. Hum Reprod. 2012;17(2):468-473.

139. Gjonnaess H. Polycystic ovarian syndrome treated by ovarian electrocautery through the laparoscope. Fertil Steril. 1984;41(1):20-25.

140. Amer SA, Li TC, Ledger WL. Ovulation induction using laparoscopic ovarian drilling in women with polycystic ovarian syndrome: predictors of success. Hum Reprod. 2004;19(8):1719-1724.

141. Amer SA, Li TC, Metwally M, Emarh M, Ledger WL. Randomized controlled trial comparing laparosopic ovarian diathermy with clomiphene citrate as a first-line method of ovulation induction in women with polycystic ovary syndrome. Hum Reprod. 2009;24(1): 219-225.

142. Farquhar C, Lilford RJ, Marjoribanks J, Vandekerckhove P. Laparoscopic 'drilling' by diathermy or laser for ovulation induction in anovulatory polycystic ovary syndrome. Cochrane Database Syst Rev. 2007;18(3):CD001122.

143. Farquhar C, Brown J, Majoribanks J. Laparoscopic drilling by diathermy of laser for ovulation induction in anovulatory polycystic ovary syndrome. Cochrane Database Syst Rev. 2012;13(6):CD001122. 
144. Heijnen EM, Eijkemans MJ, Hughes EG, Laven JS, Macklon NS, Fauser BC. A meta-analysis of outcomes of conventional IVF in women with polycystic ovary syndrome. Hum Reprod Update. 2006;12(1):13-21.

145. Al-Inany HG, Youssef MA, Aboulghar M, et al. Gonadotrophinreleasing hormone antagonists for assisted reproductive technology. Cochrane Database Syst Rev. 2011;11(5):CD001750.
146. Palomba S, Falbo A, Carrillo L, et al. Metformin reduces risk of ovarian hyperstimulation syndrome in patients with polycystic ovary syndrome during gonadotropin-stimulated in vitro fertilization cycles: a randomized, controlled trial. Fertil Steril. 2011;96(6):1384-1390.

147. Bargiota A, Diamanti-Kandarakis E. The effects of old, new, and emerging medicines on metabolic aberrations in PCOS. Ther Adv Endocrinol Metab. 2012;3(1):27-47.
Clinical Epidemiology

\section{Publish your work in this journal}

Clinical Epidemiology is an international, peer-reviewed, open access journal focusing on disease and drug epidemiology, identification of risk factors and screening procedures to develop optimal preventative initiatives and programs. Specific topics include: diagnosis, prognosis, treatment, screening, prevention, risk factor modification, systematic

Submit your manuscript here: http://www.dovepress.com/clinical-epidemiology-journal
Dovepress

reviews, risk \& safety of medical interventions, epidemiology \& biostatical methods, evaluation of guidelines, translational medicine, health policies \& economic evaluations. The manuscript management system is completely online and includes a very quick and fair peer-review system, which is all easy to use. 